\title{
Prevalence and associated factors of stunting and thinness among adolescent Somalian refugee girls living in eastern Somali refugee camps, Somali regional state, Southeast Ethiopia
}

\author{
Melaku Tadege Engidaw* (iD) and Alemayehu Digssie Gebremariam
}

\begin{abstract}
Background: Adolescence is a critical time of life stage with a continuum of physical, cognitive, behavioral and psychosocial changes. It is also a period of physical growth, reproductive maturation and cognitive transformations with the highest nutrient requirements. Among the macronutrient deficiencies, stunting and thinness are the most common nutritional problems in many parts of the world but the highest burden is in developing countries with the highest number of adolescents and the displaced population. Overall, there is a scarcity of studies on refugee adolescent girls stunting, thinness, and contributing factors. Therefore, this study aimed to fill this identified gap.

Method: Cross-sectional study design was employed. A total of 423 adolescent refugee girls were selected by using simple random sampling technique. A structured \& pre-tested questionnaire was used after translating into the Somali language to collect the data. The physical measurement of the height and the weight were done as per the standard. Descriptive statistics were employed. Variables were considered for multivariable logistic regression if a $P$-value was $\leq 0.2$ during univariate logistic regression. The odds ratio with a $95 \% \mathrm{Cl}$ was calculated and a P-value of $\leq 0.05$ was considered to declare the statistical significance of variables after fitting into the multivariable logistic regression.
\end{abstract}

Result: A total of 415 adolescent girls was included in the study with a response rate of $98.1 \%$. The overall prevalence of stunting and thinness was 9.7\% (95\% Cl: 7.0, 12.3), and 15.2\% (95\% Cl: 11.8, 18.9) respectively. The older adolescent girls were 2 (AOR: $2.10,95 \% \mathrm{Cl}: 1.12,3.93$ ) times more likely to develop stunting as compared to younger adolescents. The pre-menarcheal adolescent girls were $64 \%$ (AOR: $0.36,95 \% \mathrm{Cl}: 0.12,0.75$ ) less likely to be thin as compared to post-menarche.

Conclusion: The prevalence of stunting and thinness among adolescent refugee girls was a low and moderate public health problem respectively. The stunting was significantly associated with the age and thinness was associated with the menarcheal status of the adolescent girls. So, stakeholders should enable intervention to encourage and increase the intake of calorie-dense food adapted to adolescent's girl's age and menarcheal status.

Keywords: Refugee, Adolescent girls, Stunting, Thinness, And Somalia

* Correspondence: meltad24@gmail.com

Public Health Department, College of Health Sciences, Debre Tabor

University, P.o.box: 031 Debre Tabor, Ethiopia

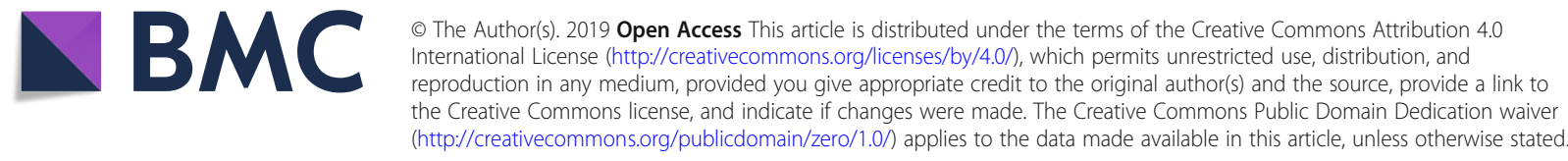




\section{Background}

Adolescence is the period between 10 and 19 years of age which again classified as younger (10 - 14 yrs) and older (15 - 19 yrs) adolescents [1]. It is a continuum of physical, cognitive, behavioral and psychosocial change that is characterized by increasing levels of individual autonomy, a growing sense of identity, self-esteem and progressive independence from adults $[2,3]$. It is a period of physical growth, reproductive maturation, and cognitive transformations in the life cycle which lead to the high requirement of macro or micronutrient or both [3-5]. The number of young people is increasing in the world and nearly half of the population in developing countries is under the age of 19 years [6]. In 2012, 1.2 billion adolescents were in this world and among them, $90 \%$ were found in developing countries with low and middle income which have a social, economic and political impact [7].

Macro and micronutrient deficiencies are due to inadequate food intake, poor nutrient content of the food and repeated infections. This problem is critical in developing countries where a majority of adolescents and displaced population is located [8-10].

Among macronutrient deficiencies, protein-energy malnutrition is one of the most common nutritional problems. The cause of protein-energy malnutrition is multifactorial but the underlining causes among children and women are the inadequate intake of foods and illness which is common among displaced and refugee community [11-14].

The deficiency of micro and/or micronutrient is very common in refugee settings since the major food sources are general ration. Due to this, women and children are vulnerable to stunting and wasting due to diseases burden, inadequate intake of nutrients and micronutrient deficiency [15-18]. The nutritional status of some refugees might be compromised because of dislocation/displacement, lack of income, and limited access to nutritious foods [15]. In Kakuma and Nepal refugee camps (in Kenya and Nepal respectively), adolescents with low BMI was 57.47 and $36.80 \%$ respectively [19]. Also, a high prevalence of low body mass index (BMI) was observed [20] which suggest the existence of wasting and stunting. Results from the first round of data collection (at the beginning of camp establishment) Sarajevo, Bosnia and Herzegovina showed a higher level of undernutrition among refugees $(15.0,95 \%$ CI $(9.95,20.05 \%))$ as compared to residents $(5.3,95 \%$ CI $(1.93,8.67 \%))$. Later, higher levels of undernutrition occurred among residents $(8.1,95 \% \mathrm{CI}(4,12.2 \%))$ as compared to the refugees $(7.0,95 \%$ CI $(3.4,10.6 \%))$ [21].

The prevalence of BMI, anemia, low vitamin A status, and signs of micronutrient deficiencies among adolescent refugees was common among the Nepalese refugee even during a fortified food distribution in the period of in 1999 due to micro or macronutrients or both [20].

The study among North Korean refugee boys and girls showed that the greatest gap observed in mid-teen years was caused by differences in growth tempos during the period of pubertal growth. The mean of weight for age $\mathrm{Z}$ score (WAZ) of the North Korean refugee adolescents was higher than their height for age $\mathrm{Z}$ score (HAZ), indicating that their growth in height is poorer than that of weight. The mean HAZ of North Korean refugee adolescents born later was not statistically significantly lower than that of those born earlier or during the famine. Those who stay in the refugee camp showed a positive effect on their growth status and suggesting that they experienced some degree of catch-up growth while they were staying in transit countries. Among all, sex, age at escape and measurement, the time interval between escape from North Korea and arrival in South Korea and year of escape were found to be significant factors in their growth status [22]. So, conducting this study is therefore very important as there are limited studies and knowledge on stunting and thinness and their associated factors among adolescent refugee girls.

\section{Methods and materials Study settings}

The Aw-Barre refugee camp is found under Eastern Somalia refugee camp coordination office in Liben Zone of the regional state. It is located $678 \mathrm{~km}$ away from Addis Ababa, the capital city of Ethiopia, $78 \mathrm{~km}$ from Jigjiga, the regional capital of the Somali regional state of Ethiopia, and $7 \mathrm{~km}$ at the border of Somalia. It was established in July 2007 by United Nation Higher Commission for Refugee (UNHCR) and Administration of Refugee and Returnee Affairs (ARRA) of Ethiopia. The camp is located at an altitude of $1621.84 \mathrm{~m}$ (5321 ft's) above sea level [23]. According to 2014 as of November ARRA report, the refugee camp had a total population of 12,803 and among this 5500 and 7382 were male and female, respectively. There are a number of different clans or ethnic groups, the majority of them were Hawuyie, Barob, Shekhal, Bantu, Asharaf, and others. Aw-Barre is one of the Eastern refugee camps in the Eastern part of Ethiopia for Somalia refugees. According to recent numbers from the camp data base report, there was a total of 1318 adolescent refugee girls aged 10-19 years in this refugee camp.

\section{Study design and period}

Cross-sectional study design was employed from February to March 2015. 


\section{Source and study population}

The source population of the study was all the adolescent girls in Somali refugee camps, and the study population was adolescent girls in Aw-Barre refugee camp.

\section{Inclusion and exclusion criteria}

All adolescent girls aged 10-19 years in Aw-Barre refugee camp were included in this study. Pregnant and lactating adolescent, adolescent with a physical disability and asylum seekers were excluded from this study.

\section{Sample size}

The sample size was calculated using a single population proportion formula. During calculation, we were considered $95 \%$ of confidence level, $50 \%$ of the proportion of Stunting and/or Thinness, and 5\% of marginal error. Then, the final sample size for this study was 423 after adding $10 \%$ of the nonresponse rate.

\section{Sampling procedures}

Among the three refugees' camps (Aw-Barre, Sheder, and Kebirebeya), Aw-Barre was selected by using the lottery method. In this camp, the total adolescent girls were 1318. A simple random sampling technique was applied to obtain the required sample size after gaining the lists of updated or revalidated adolescent refugee girls list with the respective house and block number from Aw Barre refugee and returnee affairs bureau, refugee camp database manager office to use as a sampling frame. After the random selection, the data were collected from house to house.

\section{Data collection methods and equipment}

Modified and pretested UNHCR standardized expanded nutrition survey (SENS) questionnaire was used to collect the data by interviewing the adolescent girls with their mother or caregiver. The questioner was predesigned and semi-structured. The parent's interview was taken whenever to obtain relevant information regarding the socio-demographic characteristics, health, and diseases condition, dietary pattern, and physical measurements. The questionnaire had both open and close-ended questions. The English version of the questionnaire was translated into the local language (Somali) and was translated back into the English language to check its consistency by another skilled person.

A three days training with pretest was given for the data collectors and two field supervisors on the basic skills of hemoglobin measurement, calibration of instruments, interview techniques, obtaining the written consent or assent, and precautions during the data collection time. In total, there were 2 teams comprised of a supervisor, a medical laboratory and three nurses. During training, data collectors practiced weight and height measurements on each other. Before starting data collection, always there was checking of materials and equipment. The weights and heights were measured three times by using a weight scale with height stand machine at the Frankfurt position, and then the result was recorded to the nearest $0.1 \mathrm{~kg}$ and $0.1 \mathrm{~cm}$ respectively. Then the average of the three measurements of height and weight was taken. First, the finger was wiped with alcohol-soaked cotton, and then finger pricking was done. The pricked finger was gently pressed to get a sample of $10 \mu \mathrm{l}$ blood on the HemoCuvettes and the HemoCuvetts was inserted into the HemoCueHb 301 machine. Finally, the hemoglobin level was read from the HemoCueHb 301 machine and recorded on the questionnaire. During the data collection time, communication between the data collectors, supervisors, and the principal investigators were held on a daily basis to update data collection progress.

\section{Data quality assurance}

The pre-test was done outside of the study area (at Sheder refugees' camp) on 20 samples (adolescent refugee girls) before the actual data collection period. Based on the pretest, corrective measures were done on the questionnaire. The weight scales were calibrated using $1 \mathrm{~kg}$ standard weight and the height measurements were checked with other meter taps. The HemoCueHb 301 machine was calibrated by using the 3 calibrating Hemo - solutions (EurotolHb 301 control solution which was a bovine-based solution). The pricing and taking of the sampled blood were taken after drying a weep finger by avoiding squeezing of the finger to avoiding air bubbles during filling of HemoCuvettes.

The definition of concepts and terms had been done clearly with the Somali language to avoid ambiguity. The supervisors and data collectors were recruited outside of the refugee health center to avoid information bias due to familiarization.

\section{Definitions of terms}

Poor nutritional status: when the BMI of the adolescent girl was $<18.5 \mathrm{~kg} / \mathrm{m}^{2}$ which is classified as severe, moderate and mild if the BMI $\leq 16 \mathrm{~kg} / \mathrm{m}^{2}, 16-17 \mathrm{~kg} / \mathrm{m}^{2}$ and $17-18.4 \mathrm{~kg} / \mathrm{m}^{2}$ respectively [24].

Stunting: when the adolescent girl height for age $\mathrm{Z}$ score was below -2SD from the median value of WHO reference data [25].

Thinness/wasting: when the adolescent girl BMI-for-age Z score was below -2SD from the median value of WHO reference data [25].

Anemia among adolescents: when the adjusted hemoglobin level was below $12.5 \mathrm{mg} / \mathrm{dl}$ [26] since the refugee camp is located $1000 \mathrm{~m}$ above sea level $(+0.5 \mathrm{~g} /$ dl) [27]. 
Dietary Diversity Score: was the list of foods consumed within the last $24 \mathrm{~h}$ and was categorized as low ( $\leq 3$ food groups), medium ( 4 and 5 food groups) and high dietary diversity score ( $\geq 6$ food groups) [28].

\section{Data processing and analysis}

The collected data were checked for completeness and consistency by the supervisors and the principal investigator during and after the data collection period. The data were managed by editing, verification, coding, classification, and tabulation during data entry and analysis. The data were entered into Epi info 7 and WHO AnthroPlus software. The AnthroPlus software was used to calculate the $\mathrm{Z}$ score of HAZ and BMI for age. Finally, during data analysis, four flagged cases of HAZ (when the $Z$ score is less than -6 and above +6 ) and WAZ (when the $Z$ score is less than -5 and above +5 ) were excluded from this study. After this, all the data were transported into SPSS version 20 statistical software for the descriptive and analytical analysis. A univariate logistic regression model was used to assess the independent effects of each independent variable towards the development of adolescent refugee girls stunting and thinness.

Variables with a $p$-value $\leq 0.2$ during a univariate analysis were fitted into a multivariable logistic regression model to identify the independent effect of each variable. After doing a multivariable logistic regression, a variable having a p-value of less than or equal to 0.05 was considered as a statistically significant. The odds ratio with a $95 \%$ confidence interval was used to assess the independent and multivariable effect. The Hosmer-Lemeshow goodness of fit test was performed and the $P$-value for stunting and thinness was 0.80 and 0.92 respectively.

\section{Result}

\section{Socio-demography}

Four hundred twenty-three refugee adolescent girls were selected randomly with a response rate of $415(98.10 \%)$. The mean \pm SD of age was $13.94 \pm 2.74$ years. From all, 244(58.79\%) were found between the ages of $10-14$ yrs. Only $2(0.50 \%)$ of them were involved in some activities to generate additional income. A quarter of adolescent was married (23(5.5\%)) and three quarters (305(73.5\%)) went to primary school shown in the table below (Table 1 ).

\section{Dietary diversity}

All of the respondents were using rice, spaghetti, and macaroni as a staple diet of the family. The major sources of foods were the general ration which is donated and distributed by the World Food Program (WFP) and ARRA respectively. Most of the households
Table 1 Socio-demographic characteristics of adolescent refugee girls in Aw Barre Refugee Camp, Somali Regional state, Southeast Ethiopia, 2015. $(N=415)$

\begin{tabular}{|c|c|c|c|}
\hline Variables & Categories & Number & $\begin{array}{l}\text { Percentage } \\
(\%)\end{array}$ \\
\hline \multirow[t]{2}{*}{ Age } & $10-14$ & 244 & 58.79 \\
\hline & $15-19$ & 171 & 41.21 \\
\hline \multirow{2}{*}{$\begin{array}{l}\text { Marital } \\
\text { status }\end{array}$} & Single & 392 & 94.50 \\
\hline & Married & 23 & 5.50 \\
\hline \multirow[t]{6}{*}{ Ethnicity } & Hawuyie & 103 & 24.80 \\
\hline & Asharafa & 39 & 9.40 \\
\hline & Bantu & 75 & 18.10 \\
\hline & Dir & 48 & 11.60 \\
\hline & Darod & 27 & 6.50 \\
\hline & ${ }^{\mathrm{a}}$ Other & 123 & 29.6 \\
\hline \multirow[t]{3}{*}{ Family size } & $1-4$ & 28 & 6.70 \\
\hline & $5-9$ & 222 & 53.50 \\
\hline & $10-19$ & 165 & 39.80 \\
\hline \multirow{4}{*}{$\begin{array}{l}\text { Educational } \\
\text { status }\end{array}$} & Unable to read \& write & 45 & 10.80 \\
\hline & Able to read and write & 17 & 4.10 \\
\hline & Primary school (1-8) & 305 & 73.50 \\
\hline & $\begin{array}{l}\text { Secondary school (9-12) \& } \\
\text { above }\end{array}$ & 48 & 11.60 \\
\hline \multirow{2}{*}{$\begin{array}{l}\text { Household } \\
\text { Rearing } \\
\text { Domestic } \\
\text { animals }\end{array}$} & Yes & 9 & 2.20 \\
\hline & No & 406 & 97.80 \\
\hline \multirow{2}{*}{$\begin{array}{l}\text { Selling of } \\
\text { food aid } \\
\text { items }\end{array}$} & Yes & 410 & 98.80 \\
\hline & No & 5 & 1.20 \\
\hline
\end{tabular}

aOthers: Gore, Gaboye/Maddagan, Areb, Shikal, Tumal, Samaran, Isak, Barbo, Rahawayan, Shanshi, Geladi, Moreshe, Jalele and Durukbo

${ }^{\mathrm{b}}$ To by their staple diets like Macaroni, Spaghetti, and rice

(410(98.8\%)) sold donated food to buy their staple food, and the common sold item was Wheat. A majority of respondents had a good diversity score (283 (68.2\%)) while a third had a medium or poor dietary diversity score (113 (27.2\%) and $19(4.6 \%)$ respectively.

\section{Diseases and abnormal menstruation}

None of the respondents report any acute or known chronic diseases as well as the use of medical drugs. More than half of the respondents 238(57.3\%) were started menstruation during the data collection period and from those, only $3(0.7 \%)$ of them were reporting the existence of abnormal menstruation.

\section{Nutritional status of refugee adolescent girls}

The physical measurements of the weight, height, and hemoglobin level were used to determine the nutritional status and the anemic status of all the respondents. In this study, the mean \pm Standard Deviation 
(SD) of weight, height, and Hemoglobin ( $\mathrm{Hgb})$ of respondents were $43.27 \mathrm{~kg} \pm 11.12 \mathrm{~kg}, \quad 152.15 \mathrm{~cm} \pm 9.69$ $\mathrm{cm}$, and $13.46 \mathrm{~g} / \mathrm{dl} \pm 1.48 \mathrm{~g} / \mathrm{dl}$ respectively.

The average $\pm \mathrm{SD}$ of respondents Body Mass Index (BMI) were $18.46 \pm 3.63 \mathrm{~kg} / \mathrm{m}^{2}$. Based on WHO classification, 110(26.5\%), 56(13.5\%) and 67(16.1\%) had severe, moderate and mild malnutrition with respective of their BMI. Also, the risk of overweight and obesity was $16(3.9 \%)$ and $4(1.0 \%)$ respectively. Based on the $\mathrm{Hgb}$ level, 57(13.7, 95\% CI $(10.8,17.1))$ were anemic which was a mild public health problem in this refugee camp.

One in 10 adolescent girls (9.7\% (95\% CI: 7.0, 12.3)) was stunted (HAZ $<-2$ z-score (WHO standard)) of which $1 \%$ severely stunted (HAZ $<-3 \mathrm{z}$-score). The overall mean $\pm \mathrm{SD}$ of HAZ $\mathrm{z}$ score was $-0.5 \pm 1.13$. From stunted adolescent girls, the rate of severely and moderately stunting was 1 and $8.7 \%$ respectively (Table 2 ). Older adolescents (15 - 19 yrs) (166) were more severely stunted $(1.2 \%)$ as compared to younger adolescents (249) (10 - 14 yrs), $0.8 \%$. The distribution of height for age $\mathrm{Z}$ score is illustrated in Fig. 1.

The overall wasting (BMI for age) prevalence was 15.2\% (95\% CI: 11.8, 18.9). Among wasted adolescent girls, $2.2 \%$ were severely wasted and $13 \%$ were moderately wasted. The overall mean and SD of BMI for age $\mathrm{z}$ score was $0.55 \pm 1.23$. The rate of overweight $(>+1 \mathrm{SD})$ was $11.1 \%$. The rate of wasting among younger adolescents was $19.7 \%$ and the magnitude of overweight was $10.8 \%$. On the other hand, the magnitude of wasting and overweight among older adolescents was 8.4 and 13.2\% respectively. The distribution of BMI for age $\mathrm{Z}$ score under the normal curve as illustrated in Fig. 2 below (Fig. 2).

\section{Factors associated with stunting and thinness Factors associated with stunting}

A crude analysis was done to assess the existence of an association between the independent variables and stunting of the adolescent refugee girls. In the univariate logistic regression; age and duration in the camp were positively associated with the existence of stunting. After fitting all these variables into the multivariable logistic regression, only age was the significant factor. Older adolescent girls were 2 (Adjusted Odds
Ratio (AOR): 2.10, 95\% CI: 1.12, 3.93) times more likely to develop stunting as compared to younger adolescents as shown in the table below (Table 3).

\section{Factors associated with thinness}

A crude analysis was done to assess the existence of an association between the independent variables and thinness of the adolescent refugee girls. In univariate logistic regression; age, starting menstruation, DDS and frequent use of animal products were found to be positively associated variables with the thinness of adolescent girls. After fitting these significant variables into a multivariable logistic regression, only starting menstruation was a significant factor. Adolescents who didn't start menstruating were 64\% (AOR: 0.36, $95 \% \mathrm{CI}(0.12,0.75))$ less likely to be thin/wasted compared to those who did (See in Table 3 Below).

\section{Discussion}

The prevalence of stunting and thinness was 9.7 and $15.2 \%$ which is low and moderate public health problem respectively based on this finding. In this study, the magnitude was very low as compared to a study done among Nepal refugees (>60\%) [29] but higher as compared to North Korean refugees [30]. In this study, the magnitude of wasting was comparable with a study done in Wukro, Northern Ethiopia, and the result was $21.6 \%$ (95\% CI: 15.8, 27.3\%). But, the magnitude of stunting was $21.2 \%$ (95\% CI: 15.8, 27.3\%) which is high as compared to our study [31]. This may be due to variation in setting, data collection time, child labor among Nepalese adolescents and duration in the camp with food aid.

Older adolescent girls were 2 (AOR: 2.10, 95\% CI (1.12, 3.93) times more likely to develop stunting as compared to younger adolescents. Similarly, it is true among North Korean refugees who were older North Korea children were more likely, and those who lived in South Korea longer were less likely, to be currently stunted [30]. This may be due to the inadequate intake of nutrients during infancy, and childhood strongly affects the linear growth of the recommended height as the respective age. Also, the chronic and cumulative shortage of food, the

Table 2 Magnitude of stunting and thinness among adolescent refugee girls in the Aw-Barre Somalia refugee camp, Somali Regional state, Southeast Ethiopia, 2015

\begin{tabular}{|c|c|c|c|c|c|c|c|c|c|c|c|}
\hline \multirow{2}{*}{$\begin{array}{l}\text { Age } \\
\text { (yrs) }\end{array}$} & \multicolumn{4}{|c|}{ HFA with $95 \% \mathrm{Cl}$} & \multicolumn{7}{|c|}{$\%$ of BMl for Age with $95 \% \mathrm{Cl}$} \\
\hline & $<-3 \mathrm{SD}$ & $<-2 S \mathrm{SD}$ & Mean & SD & $<-3 \mathrm{SD}$ & $<-2 \mathrm{SD}$ & $<+1 S D$ & $<+2 \mathrm{SD}$ & $<+3 S D$ & Mean & SD \\
\hline$\overline{10-14}$ & $0.8(0,2.1)$ & $8.8(5.1,12.6)$ & -0.39 & 1.23 & $3.2(0.8,5.6)$ & $16.5(11.7,21.3)$ & $8.8(5.1,12.6)$ & $2(0.1,4)$ & $0(0,0.2)$ & -0.69 & 1.26 \\
\hline $15-19$ & $1.2(0,3.2)$ & $8.4(3.9,13)$ & -0.66 & 0.94 & $0.6(0,2.1)$ & $7.8(3.4,12.2)$ & $10.8(5.8,15.9)$ & $1.8(0,4.1)$ & $0.6(0,2.1)$ & -0.34 & 1.16 \\
\hline Total & $1(0,2)$ & $8.7(5.8,11.5)$ & -0.5 & 1.13 & $2.2(.06,3.7$ & $13(9.7,16.4)$ & $9.6(6.7,12.6)$ & $1.9(0.5,3.4)$ & $0.2(0,0.8)$ & -0.55 & 1.23 \\
\hline
\end{tabular}

HFA Height For Age, BMI Body Mass Index, SD Standard Deviation, Cl Confidence Interval 


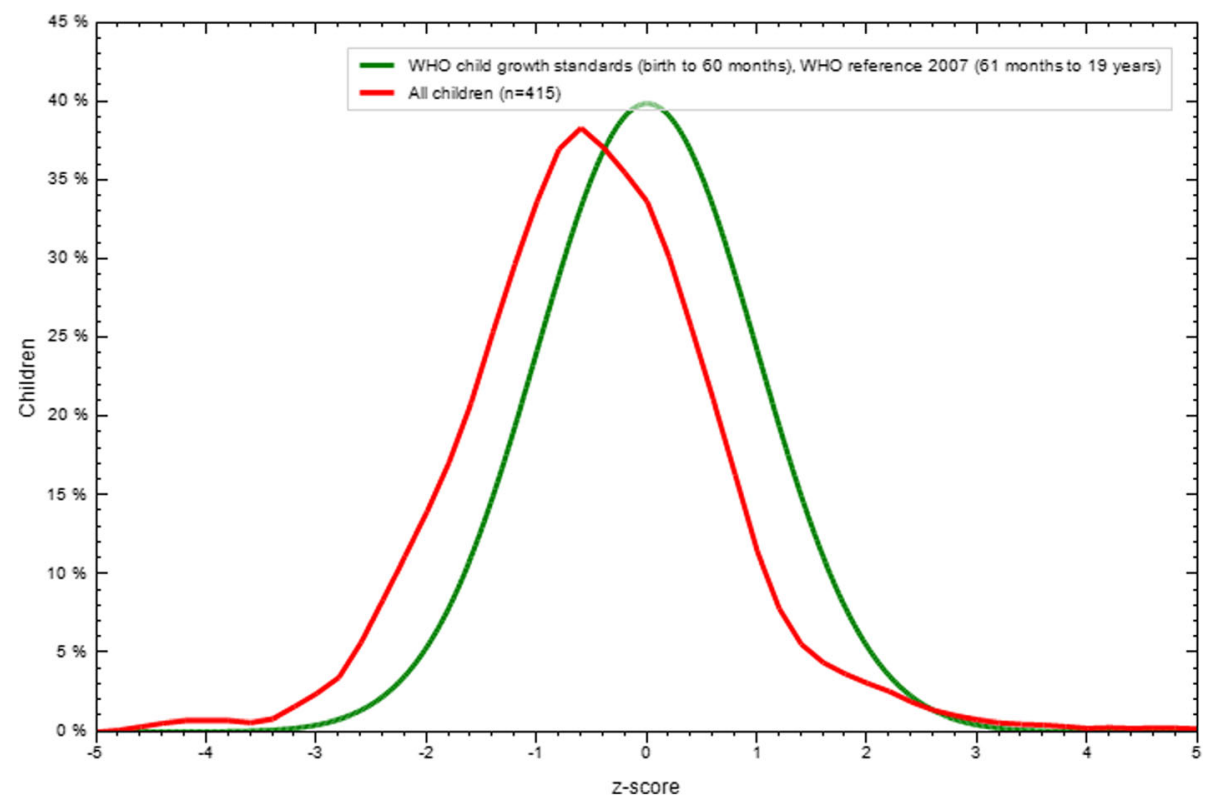

Fig. 1 Height for age result for adolescent refugee girls in Aw - Barre Refugee Camp, Somali Regional state, Southeastern Ethiopia, 2015

shortages of basic medicine and fuel, the damage to the infrastructure from wars and the difficult economic circumstances of Somalia might pose substantial challenges to the later life of the adolescent girls' nutritional status.

Adolescents who didn't start menstruating were 64\% (AOR: $0.36,95 \%$ CI $(0.12,0.75)$ ) less likely to be thin/wasted compared to those who did. Other studies reveal that nutrient deficiency due to menstrual loss, erratic eating habits and preference of foods at the transition age of girls is a common cause for thinness $[32,33]$. This may be due to changing habits of food intake because of menstrual-related sign and symptoms and peer influence on food preferences as well as the existence of monotonous family diet due to general ration might be lead to decrement in weight gain which directly affects the BMI for the age of the adolescent girls.

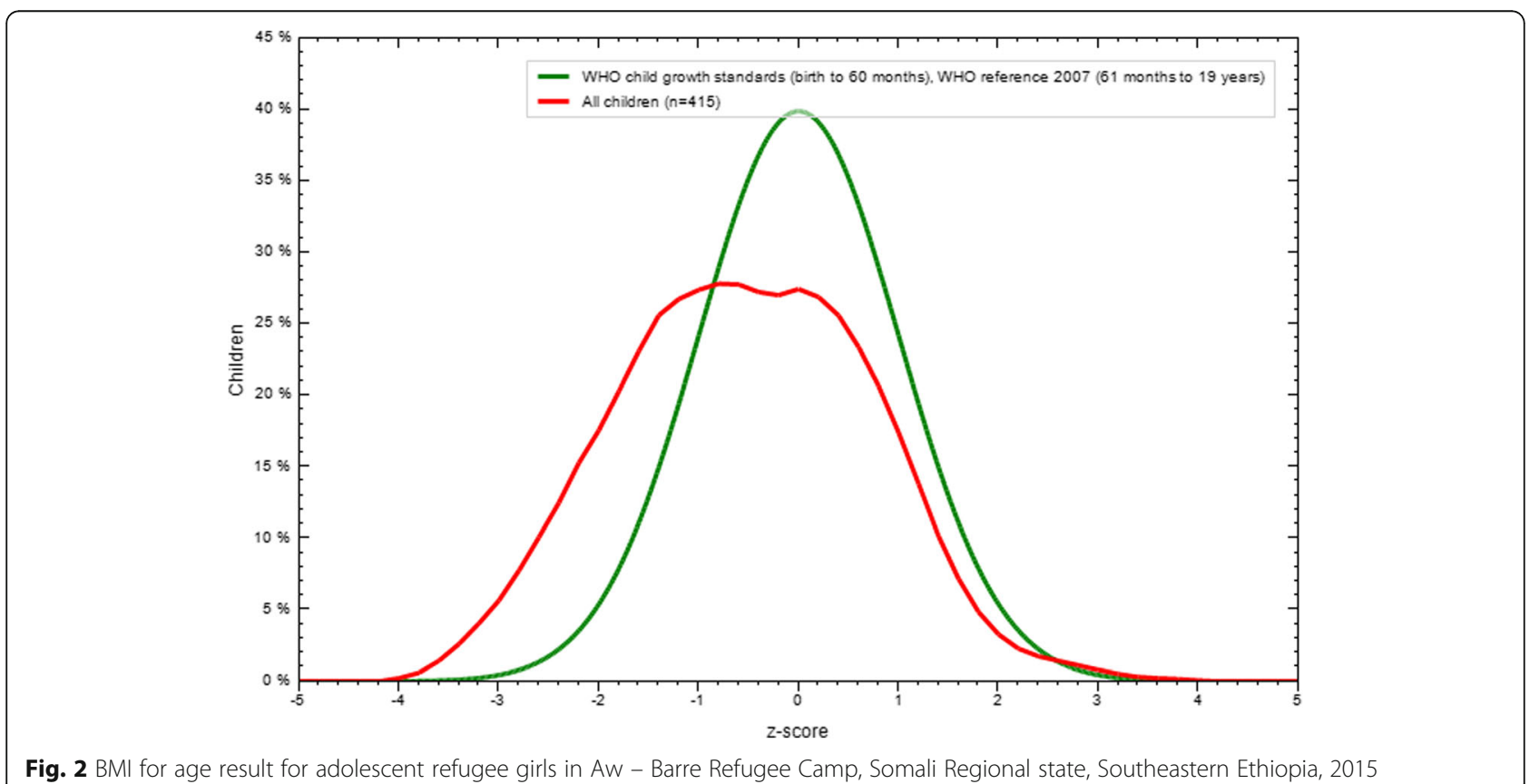


Table 3 Logistic regression result of associated factors with stunting and thinness among adolescent refugee girls of Aw-Barre Somalia refugee camp, South East Ethiopia, 2015

\begin{tabular}{|c|c|c|c|c|c|}
\hline \multicolumn{6}{|c|}{ Logistic regression result for Stunting } \\
\hline \multirow[t]{2}{*}{ Variables } & \multirow[t]{2}{*}{ Category } & \multicolumn{2}{|c|}{ Stunting } & \multirow[t]{2}{*}{$\operatorname{COR}(95 \% \mathrm{Cl})$} & \multirow[t]{2}{*}{ AOR $(95 \% \mathrm{Cl})$} \\
\hline & & Yes & No & & \\
\hline \multirow[t]{2}{*}{ Age } & $10-14$ & 19 & 225 & 1 & 1 \\
\hline & $15-19$ & 26 & 145 & $2.12(1.13,3.97)$ & $2.10(1.12,3.93)^{*}$ \\
\hline \multirow[t]{2}{*}{ Duration in the camp (median) } & $<8$ yrs & 5 & 66 & $0.58(0.22,1.51)$ & $0.60(0.22,1.58)$ \\
\hline & $\geq 8 \mathrm{yrs}$ & 40 & 304 & 1 & 1 \\
\hline \multicolumn{6}{|c|}{ Logistic regression result for Thinness (Wasting) } \\
\hline \multirow[t]{2}{*}{ Variables } & \multirow[t]{2}{*}{ Category } & \multicolumn{2}{|c|}{ Wasting } & COR $(95 \% \mathrm{Cl})$ & AOR $(95 \% \mathrm{Cl})$ \\
\hline & & Yes & No & & \\
\hline \multirow[t]{2}{*}{ Age in years } & $10-14$ & 44 & 200 & 1 & 1 \\
\hline & $15-19$ & 19 & 152 & $0.46(0.25,0.84)$ & $1.13(0.53,2.40)$ \\
\hline \multirow{3}{*}{$\begin{array}{l}\text { Frequency of using protein-rich } \\
\text { food sources }\end{array}$} & used within 2 weeks & 4 & 50 & 1 & 1 \\
\hline & used in a month & 38 & 219 & $2.17(0.74,6.35)$ & $1.88(0.63,5.59)$ \\
\hline & Didn't use within a month & 21 & 83 & $3.16(1.03,9.75)$ & $2.60(0.82,8.18)$ \\
\hline \multirow[t]{3}{*}{ Dietary diversity score/DDS } & $\leq 3$ foods items & 01 & 18 & $0.27(0.04,2.03)$ & $0.26(0.33,2.02)$ \\
\hline & $4-5$ food items & 13 & 100 & $0.62(0.32,1.19)$ & $0.64(0.33,1.24)$ \\
\hline & $\geq 6$ food items & 49 & 234 & 1 & 1 \\
\hline \multirow[t]{2}{*}{ Menarcheal status } & Post menarche & 23 & 215 & $0.37(0.21,0.63)$ & $0.36(0.12,0.75)^{*}$ \\
\hline & Pre menarche & 40 & 137 & 1 & 1 \\
\hline
\end{tabular}

*Significant at $\mathrm{p}$ valve $\leq 0.05,1=$ reference, COR Crude Odd Ratio, AOR Adjusted Odd Ratio, Cl Confidence Interval

\section{Conclusion and recommendation}

The prevalence of stunting among adolescent refugee girls was a low but thinness or wasting was a moderate public health problem. In this study, the factors associated with the development of stunting were age and for thinness was menarcheal status.

Based on the finding, UNCHR/WFP/ARRA will consider increasing the intake of high caloric food sources with varieties to reduce the prevalence and its intergenerational effect through food fortification, cash transfer and the strengthening of nutrition and public health programs among long-term food aid dependent adolescent refugee girls. Also, the ongoing practice of conducting annual or periodic surveys by stakeholders (UNCHR/WFP/ARRA) among food aid beneficiaries of adolescent girls at least by using anthropometric measurement is important to monitor the prevalence/ magnitude.

Health professional should have to provide health and nutrition education and counseling based on age and menarcheal status of adolescent girls by integrating with other reproductive health care services.

\section{Abbreviations}

AOR: Adjusted Odds Ratio; BMI: Body Mass Index; COR: Crude Odds Ratio; DDS: Dietary Diversity Score; HAZ: Height for Age Z score; Hgb: Hemoglobin; SD: Standard Deviation; SPSS: Statistical Packages for Social Sciences;
UNHCR: United Nation Higher Commission for Refugee; WAZ: Weight for Age Z score; WHO: World Health Organization

\section{Acknowledgments}

We deeply acknowledge all the study participants, all the staffs of ARRA at all level and especially for Sennay Bahita, supervisors and all data collectors for their cooperation and commitment to the success of this study.

\section{Funding}

No fund is accepted from any organization.

\section{Availability of data and materials}

The datasets are available from the authors. So, we can provide the data at any time during the request.

\section{Authors' contribution}

MTE: made the draft of the proposal, and acquisition, analysis of data and on the interpretation or discussion of results and the whole parts of the manuscript. ADG: worked on the analysis of data, on the interpretation or discussion of results and revising the whole manuscript. All the authors read and approved the final manuscript.

\section{Ethics approval and consent to participate}

Ethical clearance and permission were obtained from the Institutional Ethical Review Committee of Debre Tabor University, and the official letter was obtained from Refugee and returnee affairs of Ethiopia. Informed consent and/or assent were obtained from the study participants. The purpose of the study was explained to them. Lastly; before starting the interview and taking a measurement, we informed each participant that they had the right to withdraw from the study at any time. They were assured that the sampled blood was used to measure the Hgb level in front of the study participants. Finally, after measuring and recording the hemoglobin level, the sample was immediately discarded into the disposal safety box in front of the study participants. The confidentiality was maintained at all levels of the study by 
avoiding personal identifier. Finally, we assured that the final result would be published and presented for the scientific community. Anemic and wasted adolescent girls were referred to the refugee health center by using an internal referral slip of the refugee health center, and the advice was given on the importance of appropriate nutrition by the data collectors.

\section{Consent for publication}

Not applicable to this section.

\section{Competing interests}

We declare that there is no competing interest with anyone else.

\section{Publisher's Note}

Springer Nature remains neutral with regard to jurisdictional claims in published maps and institutional affiliations.

Received: 20 February 2018 Accepted: 7 May 2019

Published online: 17 May 2019

\section{References}

1. WHO, Young People's Health. A Challenge for Society, WHO Technical Report 1986, WHO: Geneva, Switzerland.

2. Mitchell, K., Adolescent sexual and reproductive health a toolkit for humanitarian setting, A Companion to the Inter-Agency Field Manual on Reproductive Health in Humanitarian Settings. Save the children and UNFPA, 2009.

3. WHO, Physical status: the use and interpretation of anthropometry, in WHO technical reports 854. 1995, World health organization: Geneva. p. 263-274.

4. Whitney E, Rolfes RS. Understanding Nutrition. 11 ed. USA: Thomson Wadsworth; 2008. p. 575-7.

5. Mann, J., Truswell, S., Essentials of human nutrition. 2 ed. 2002, New York: Oxford University Press Inc. 536-539.

6. State of the world population, 2014 in THE POWER OF1.8 billion Adolescents, Youth and the transformation of the future B. Osotimehin, Editor. 2014, UNFPA: New York. P. 13-20.

7. UNICEF, Progress for Children: A report card on adolescents. April 2012, United Nations Children's Fund: 3 United Nations Plaza, New York, NY 10017, USA.

8. WHO, the Worldwide prevalence of anemia 1993-2005 WHO Global Database on Anaemia. 2008.

9. UNHCR, UNHCR Strategic Plan for Anaemia Prevention, Control and reduction, Reducing the Global Burden of Anaemia in Refugee Populations 2008 - 2010. 2008.

10. Stuetz W, et al. Micronutrient status in lactating mothers before and after the introduction of fortified flour: cross-sectional surveys in Maela refugee camp. Eur J Nutr. 2012;51(4):425-34.

11. Orach CG. Morbidity, and mortality amongst southern Sudanese in Koboko refugee camps, Arua District, Uganda. East Afr Med J. 1999;76(4):195-9.

12. Porignon $D$, et al. The unseen face of the humanitarian crisis in the eastern Democratic Republic of Congo: was nutritional relief properly targeted? J Epidemiol Community Health. 2000;54(1):6-9.

13. Rossi L, Mangasaryan N, Branca F. Nutritional status and poverty assessment of vulnerable population groups in Armenia. Soz Praventivmed. 2005;50(3): 166-76.

14. Sanati Pour M, et al. Prevalence of dyslipidemia and micronutrient deficiencies among newly arrived afghan refugees in rural Australia: a crosssectional study, vol. 14: BMC Public Health; 2014. p. 896.

15. Bilukha $\mathrm{OO}$, et al. Nutritional status of women and child refugees from Syria-Jordan, April-may 2014. MMWR Morb Mortal Wkly Rep. 2014;63(29): 638-9.

16. Geltman $\mathrm{PL}$, et al. Growth status and related medical conditions among refugee children in Massachusetts, 1995-1998. Am J Public Health. 2001; 91(11):1800-5

17. Tiong AC, et al. Health issues in newly arrived African refugees attending general practice clinics in Melbourne. Med J Aust. 2006;185(11-12):602-6.

18. Woodruff BA, Duffield A. Anthropometric assessment of nutritional status in adolescent populations in humanitarian emergencies. Eur J Clin Nutr. 2002; 56(11):1108-18.

19. Woodruff BA, et al. Anaemia, iron status and vitamin a deficiency among adolescent refugees in Kenya and Nepal. Public Health Nutr. 2006;9(1):26-34.
20. CDC, Nutritional assessment of adolescent refugees--Nepal, 1999. MMWR Morb Mortal Wkly Rep. 2000;49(38):864-7.

21. Smaijkic $A$, et al. Changes in nutrition among residents and refugees in Sarajevo during the war. Eur J Clin Nutr. 1995;49(Suppl 2):S17-22.

22. Pak S. The growth status of north Korean refugee children and adolescents from 6 to 19 years of age. Econ Hum Biol. 2010;8(3):385-95.

23. Rage IA. based on experience in conducting nutrition surveys in Rwanda UNHCR regional support hub Nairobi; 2012.

24. $\mathrm{WHO}, \mathrm{WHO}$ child growth standards: length/height for age, weight-for-age, weight-for-length, weight-for-height, and body mass index-for-age, methods and development. 2006: World Health Organization.

25. Onis Md, et al. Development of a WHO growth reference for school-aged children and adolescents. Bull World Health Organ. 2007:85:660-7.

26. World Health Organisation, Nutritional anemia. Report of a WHO scientific group Geneva. Switzerland: World Health Organisation; 1968.

27. $\mathrm{WHO}$, Haemoglobin concentrations for the diagnosis of anemia and assessment of severity. Vitamin and Mineral Nutrition Information System. Geneva, World Health Organization, 2011. WHO/NMH/NHD/MNM/11.1.

28. Swindale A, Bilinsky P. Household dietary diversity score (HDDS) for measurement of household food access: indicator guide. Washington, DC: Food and Nutrition Technical Assistance Project, Academy for Educational Development; 2006.

29. Doocy S, et al. The risks and impacts of Portering on the well-being of children in Nepal, vol. 53: Oxford University Press; 2007. p. 3.

30. Lee S-K, Nam S-Y, Hoffman D. Changes in nutritional status among displaced north Korean children living in South Korea. Ann Hum Biol. 2015:42(6):581-4.

31. Melaku YA, et al. Prevalence and factors associated with stunting and thinness among adolescent students in Northern Ethiopia: a comparison to World Health Organization standards archives of public health, vol. 73; 2015. p. 44.

32. Kaur S, Deshmukh P, Garg BS. Epidemiological correlates of nutritional anemia in adolescent girls of rural Wardha. Indian J Community Med. 2006; 31:255-8.

33. Kishore J. National Health Programs of India. In: Century publications: New Delhi; 2006. p. 82-4.

\section{Ready to submit your research? Choose BMC and benefit from:}

- fast, convenient online submission

- thorough peer review by experienced researchers in your field

- rapid publication on acceptance

- support for research data, including large and complex data types

- gold Open Access which fosters wider collaboration and increased citations

- maximum visibility for your research: over $100 \mathrm{M}$ website views per year

At BMC, research is always in progress.

Learn more biomedcentral.com/submissions 